Kocaeli Üniversitesi Sağlık Bilimleri Dergisi

\title{
FITNESS YAPAN SPORCULARA UYGULANAN POWER PLATE VE BOTH SIDES UP EGZERSIZLERININ DENGE GELIŞIMINE ETKİSI
}

\author{
THE EFFECT OF POWER PLATE AND BOTH SIDES UP EXERCISES ON BALANCE DEVELOPMENT \\ OF FITNESS ATHLETES
}

\author{
@(iD) Selami Uçar*1, (iD) Betül Bayazıt ${ }^{2}$
}

\begin{abstract}
${ }^{1}$ Kocaeli Üniversitesi, Sağlık Bilimleri Enstitüsü, Sporda Performans ve Kondisyon Programı/Beden Eğitimi ve Spor Anabilim Dalı, Kocaeli, Türkiye ${ }^{2}$ Kocaeli Üniversitesi, Spor Bilimleri Fakültesi, Kocaeli, Türkiye
\end{abstract}

ORCID iD: Selami Uçar: 0000-0003-3274-1930; Betül Bayazit: 0000-0003-3547-2035

*Sorumlu Yazar / Corresponding Author: Selami Uçar e-posta / e-mail: selamiucarrr@gmail.com

Geliş Tarihi / Received: 15.06.2021 Kabul Tarihi / Accepted: 13.07.2021 Yayım Tarihi / Published: 31.10 .2021

Öz

Amaç: Fitness merkezine düzenli gelen bireylere uygulanan power plate ve both sides up (boşu) egzersizlerinin denge gelişimine etkisinin incelenmesidir.

Yöntem: Araştırmanın çalışma grubu, fitness merkezine düzenli gelen 18-35 yaş aralığında 40 erkek katılımcıdan oluşmaktadır. Gönüllü olarak çalışmaya katılan katılımcılar tesadüfi yöntemle 10'ar kişilik 4 gruba ayrılmıştır. Bu gruplar, 10 kişi power plate deney, 10 kişi power plate kontrol ve 10 kişi bosu deney, 10 kişi bosu kontrol grubundan oluşmaktadır. Araştırma gruplarına boy, vücut ağırlığı, vücut yağ oranı, alt-üst ekstremite uzunluk, Y Denge, Fonksiyonel Uzanma ve Flamingo test ölçümleri yapılmıştır. Deney gruplarına, haftada 3 gün, günde bir saat olarak toplam 12 hafta çalışmalar yapılmıştır. Kontrol grubu 12 hafta süre ile uygulamaların dışında tutulmuştur.

Bulgular: Araștırmada, deney gruplarında vücut ağırlığı, vücut yağ oranı, Y Denge, Fonksiyonel Uzanma ve Flamingo son test ortalama sonuçları arasında anlamlı farklılık bulunmuştur $(p<0,05)$. Kontrol gruplarında vücut ağırlıgı, vücut yağ oranı, Y Denge, Fonksiyonel Uzanma ve Flamingo son test ortalama sonuçları arasında anlamlı farklılık bulunmamıştır $(p>0,05)$. Bosu ve power plate kontol grupları ön test ile son test ortalama sonuçları arasında anlamlı farklılık bulunmamıştır $(p>0,05)$. Bosu ve power plate deney grupları ön test sonuçlarında anlamlı farklılık bulunmazken, son test ortalama sonuçları arasında vücut yağ oranında anlamlı bir farklılık bulunmuştur $(p<0,05)$.

Sonuç: Vücut ağırlığı ile uygulanan bosu ve power plate üzerinde yapılan düzenli ve sistemli egzersizlerin bireylerin denge değerlerinde bir farklılığın oluştuğunu göstermektedir. Ayrıca vücut ağırlığı ve vücut yağ oranında anlamlı oranda azalma olduğu gözlemlenmiştir.

Anahtar Kelimeler: Denge, bosu, power plate, y denge, flamingo.

\begin{abstract}
Objective: This is the study of the effect of power plate and both sides up (bosu) exercises on balance development, applied to individuals who come to the fitness center regularly.

Method: The study group of the research consists of 40 male participants between the ages of 18-35 who regularly come to the fitness center. Participants who participated in the study voluntarily were randomly divided into 4 groups of 10 people. These groups consist of 10 person power plate test subject, 10 person power plate control group and 10 person bosu test subject, 10 person bosu control group. Height, body weight, body fat rate, lower extremity length, upper extremity length, Y Balance, Functional Reaching and Flamingo test measurements were applied to the participants. The test subject groups were studied 3 days a week, one hour a day, for a total of 12 weeks. Control group was excluded from the applications for 12 weeks.

Results: In our study, statistically reasonable differences were found between the mean results of body weight, body fat rate, Y Balance, Functional Reaching and Flamingo post test in the subject groups $(p<0.05)$. In the control groups, no statistically reasonable difference were found between the mean results of body weight, body fat rate, Y Balance, Functional Reaching and Flamingo post test ( $p>0.05)$. No statistically reasonable difference were found between the pre test and post test mean results of Bosu and Power Plate control groups $(p>0.05)$. While there was no statistically reasonable difference in the pre test results of the Bosu and Power Plate subject groups, statistically reasonable differences was found between the post test mean results $(p<0.05)$.

Conclusions: Regular and systematic exercises applied with body weight, bosu ball and power plate show that there is a difference in the balance values of individuals. In addition, a significant decrease in body weight and body fat was observed.
\end{abstract}

Keywords: Balance, bosu, power plate, y balance, flamingo. 


\section{Giriş}

Kişinin günlük yaşam aktivitelerini başarılı ve bağımsız olarak gerçekleştirebilmesi için dengesinin iyi olması gerekir. Spor bilimi açısından; amaçlanan hareket için, merkezi sinir sistemi ile iskelet-kas sisteminin karşılıklı uyum içinde etkileşimi gerekir. ${ }^{1}$ Denge, vücudun sabit bir pozisyonda kalma yeteneği veya yerçekimine karşı koyarak kararlı hareketler yapabilmesidir. ${ }^{2}$ Denge yetisi hemen hemen bütün spor branşlarının koşulu olduğu gibi günlük hayatta da büyük bir öneme sahiptir. İyi bir denge, özellikle günlük yaşamda pek çok aktiviteyi etkileyen önemli bir unsurdur. Kişi dengede durmak için öne yana hafif hafif salınır. Alt ekstremiteler vücudu her zaman desteklemektedir. Kaslar dengenin devamlı kontrolü için önemli görev üstlenirler. Bu da fleksör ve ekstensör kasların sinergist ve antagonist bir şekilde çalışması ile mümkün olur. Denge ve duruş vücudu düşme riskine karşı uyarır. Vücut postürü değiştiği zaman, vücut hemen tepki gösterir. ${ }^{3}$

Denge sisteminin temel özelliği, baş hareketleri esnasında görme alanını sabitlemek ve yerçekimine rağmen vücudu kontrol etmektir. Vücut denge kontrolünde, vestibüler ve görsel sistem baskın rol oynar. Vestibüler, görsel ve somatosensoriyel sistemden gelen uyarıların merkezi sinir sistemi'nde işlenerek kas-iskelet sisteminde uygun cevapların açığa çıkarılmasıyla denge sistemi oluşur. ${ }^{4}$

Dengeyi etkileyen faktörler; içsel ve dişsal etmenlerden oluşur. Bu sebeple, egzersiz sıklığı ve bireyin propriyoseptif ve görsel algılama kapasitesi denge özelliğini etkiler. ${ }^{5}$ Sağlıklı bireylerde verilen denge eğitimi ile fonksiyonel testlerde gelişimin gösterilmesi nedeniyle günlük yaşam aktiviteleri ve sportif performansin artırılmasında kullanılabileceği belirtilmektedir. ${ }^{6}$ Egzersiz programları yapılırken dengenin geliştirilmesi için hareketli ve hareketsiz zeminlerde yapılan antrenman programlarının bir parçası haline gelmiştir. ${ }^{7}$

Yapılan araştırmalarda denge egzersizlerinin farklı yöntem ve aletlerle yapıldığ 1 görülmektedir. Ayakta, oturarak, diz çökerek yapıldığı gibi, yumuşak ve sert zeminlere sahip haraketli nesneler (power plate, denge diski, bosu topu ve isviçre topu gibi) ile farklı türde denge egzersizleri çalışılmıştır. 5,8,9 $^{-1}$

Bu bağlamda araştırmanın amacı; fitness merkezine düzenli gelen bireylere uygulanan power plate ve bosu egzersizlerinin denge gelişimi için ne gibi değişimler olduğunu belirlemektir.

\section{Power Plate}

Vibrasyon, bir cismin dinlenik konumuna göre düzenli veya düzensiz olarak oluşturduğu periyodik hareketlerle meydana gelen mekanik salınımlar olarak tanımlanmaktadır. ${ }^{10}$ Hareket sırasında kaslarda bulunan kas iğcikleri uyarılarak $\alpha$-motor nöronların aktivasyonu ile tonik vibrasyon refleksi gerçekleşir ve kas kasılır. ${ }^{11}$ Vibrasyon cihazı olan power plate, kas içi ve kaslar arasındaki koordinasyonu sağlayan tüm reseptörlerin aynı anda uyarılmasını sağlar. Bir başka deyişle, çalışma bölgesinin tümünde "istem dış1 kasılmalara" neden olur. Böylelikle vücudun koordinasyon yeteneği ve uyumu artar, buna bağlı olarak tepki ve denge hissi gelişir. ${ }^{12}$ Ayrıca power plate, metabolizmanın zenginleşmesine neden olur, yağ yakılmasını hızlandırır, ana metabolizmayı düzenleyerek deri altındaki yağ tabakasını azaltır. ${ }^{13}$

\section{Bosu Ball}

BOSU (Both Sides Up) sportif ve rekreasyonel aktif nüfusun denge eğitimi için tasarlanmış bir aparattır. BOSU, sabit zeminde stabil olmayan sert bir yüzeye sahiptir. Farklı denge eğitimleri için, düz platform tarafı da kullanılabilir. Ayrıca, kullanıcı sadece dikey pozisyonunu korurken değil, aynı zamanda yatay konumda olduğunda da stabilitesini geliştirmek için tasarlanmıştır. ${ }^{14}$ Yarım daire şeklinde ve içi hava dolu bir top olan bosu topunun tabanı sert ve düz bir plastikten oluşmaktadır. ${ }^{15}$ BOSU egzersizleri vücuttaki kan dolaşımının hızlanmasına katkı sağlar. Ayrıca vücutta yăg yakımı, kan dolaşımı, kilo verme, kilo alma ve kas gelişiminin sağlanmasında da etkilidir. ${ }^{16}$

\section{Yöntem}

\section{Araştırma Grubu}

Araştırma grubunu, Ağaoğlu My Clup Spor Salonu'na düzenli gelen ve araştırmaya gönüllü olarak katılmak isteyen bireylerden tesadüfi yöntemle seçilen 18-35 yaş aras1 40 sedanter erkek birey oluşturmaktadır. Power plate kontrol grubu (10 kişi) ve deney grubu (10 kişi) desenine göre iki gruba ayrılmıştır. Bosu ball kontrol grubu (10 kişi) ve deney grubu (10 kişi) desenine göre iki gruba ayrılmıştır. Deney grubuna 12 hafta boyunca haftada 3 gün günde bir saat olmak üzere düzenli fiziksel aktivite programı uygulanmıştır. Kontrol grubuna herhangi bir fiziksel aktivite programı uygulanmamıştır.

Katılımcıları belirlerken herhangi bir fiziksel engeli olmayan, spor yapmasında sakıncası olacak sağlık geçmişi bulunmayan, epilepsi geçmişi, uyku problemi ve beslenme problemi olmayan bireylerden tercih edilmiştir.

\section{Verilerin Toplanması ve Prosedür}

$\mathrm{Bu}$ araştırma, deneysel yöntem içerisinde yer alan ön test-son test kontrol gruplu modelinden olup, eşleştirilmiş seçkisiz desene göre tasarlanmış deneysel bir nitelik taşımaktadır. Bu araştırma fitness merkezine düzenli gelen bireylerin gönüllü olarak katılımıyla gerçekleştirilmiş olup, bireylere araştırmaya katılıma dair bilgilendirilme yapılarak, bir onay formu imzalatılmış, gerekli resmi izinler alınmıştır. Araştırmanın etik onayı, Kocaeli Üniversitesi Girişimsel Olmayan Klinik Araştırmalar Etik Kurulu'ndan 2019/61 sayıl1 proje numarası ve 2019/04.14 karar numarası ile 20.02.2019 tarihinde alınmıştır. Helsinki Bildirgesi'nin insan araştırmaları etik standartlarına uygun şekilde yerine getirilmiştir.

Araştırmaya katılan evren grubuna antropometrik ölçümler (vücut ağırlığı, vücut yăg oranı, boy uzunluğu, alt-üst ekstremite uzunluk ölçümü) yapılmıştır. Ayrıca, flamingo denge testi, y denge testi ve fonksiyonel uzanma testi uygulanmıştır.

\section{Genel Test Kuralları}

Ölçümler alındıktan sonra çalışmaya katılan bireylere deney süresi boyunca yapacakları hareketler ve bu hareketlerin doğru formu hakkında bilgilendirme yapılmış, hareketlerin en doğru şekilde yapılması noktasında bir standart oluşturulmaya çalışılmıştır.

\section{Antropometrik Ölçümler}

Boy ölçümü: SECA marka boy ölçer aleti ile ölçülmüştür. Boy ölçere sırtlarını dönüp ayaklar çıplak şekilde başlangıç vaziyeti alınmış olup daha sonra sonuç santimetre cinsinden not edilmiştir.

Üst ekstremite uzunluk ölçümü: MIZY marka mezura ile omuz bölgesindeki akromiyon çıkıntısı ile elin orta parmağı arasında, kollar açık şekilde avuç içi gövdeye dönük biçimde ölçüm yapılmıştır. 
Alt ekstremite uzunluk ölçümü: MIZY marka mezura ile alt ekstremite ölçümü yapılan birey ayakta iken anterior superior iliac spine noktası başlangıç, medial malleolus noktası bitiş noktası olarak referans alınmıştır.

Ăğırlık ve yağ oranı ölçümü: Bireylerin vücut ağırlıkları ve yağ oranları ayaklar çorapsız şekilde ve üzerlerinde spor kıyafetleri ile alınmıştır. Bu sebeple dara ağırlığı $1 \mathrm{~kg}$ girilmiştir. Ölçüm esnasında BIA (Bioelektrik İmpedans Analizi) yöntemi kullanılmış olup cihazın markası TANITA, modeli ise BC-418'dir. Sonuçlar yağ oranı bakımından segmental olarak ve toplam ağırlık kilogram cinsinden belirtilmiştir.

\section{Flamingo Denge Testi}

Bireylerin statik dengesi değerlendirilmiştir. Testin geçerlilik ve güvenilirliğini ICC (Intraclass Correlation Coefficient), oranını 0,71 olarak belirlenmiştir. ${ }^{17}$ Test bireyin dominant ekstremitesi üzerinde uygulanmıştır. Öncelikle testin içeriği

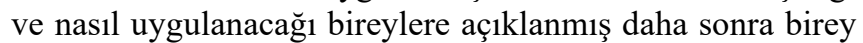
literatürde belirtilen ölçülerde hazırlanan, $50 \mathrm{~cm}$ uzunluğunda, $3 \mathrm{~cm}$ genişliği ve $4 \mathrm{~cm}$ yüksekliği olan ahşap kiriş üzerinde dengede durmaya çalışırken, bireyin 1 dakika içinde kaç defa düştüğü hesaplanmıştır. Bu süre içinde her düşme esnasında kronometre durdurularak tekrardan bireyin pozisyon alması beklenmiştir. Tekrar denge pozisyonuna geçmesi için yardım edilerek kronometre başlatılmıştır.

\section{Y Denge Testi}

Y Denge Testi: Bireylerin dinamik dengesi değerlendirilmiştir. Testin geçerlilik güvenilirliği ICC, aralığ1 intrarater $0,85-0,01$ ve interrater aralığ1 0,99-1,00 olarak belirlenmiştir. ${ }^{18}$ Testin içeriği ve nasıl uygulanacağı bireylere açıklanmış daha sonra birey literatürde belirtilen ölçülerde hazırlanan, $35 \mathrm{~cm}$ uzunluğunda, $13 \mathrm{~cm}$ genişliği ve $4 \mathrm{~cm}$ yüksekliğinde ahşap kirişe sabitlenmiş, 3 farklı yönde bulunan 2 metre uzunluğunda olan Y Denge Kiti üzerinde bireylerin sağ ve sol ekstremiteleri üzerinde uzanma miktarları ölçülmüştür. Bireyden test düzeneğinin orta noktasında tek ayak üzerinde durarak diğer ayağı ile anterior, posteromedial, posterolateral yönlere doğru dengesini koruyarak ayak parmak ucu ile uzanabildiği ve eski pozisyonuna dönebildiği maksimum değer ölçülmüştür. Test her yöne $3 \mathrm{kez}$ tekrar edilerek her yönün kendi içinde ortalamaları alınmış ve cm cinsinden kaydedilmiştir.

\section{Fonksiyonel Uzanma Testi}

Bireyin fonksiyonel olarak hem dengesini hem de dinamik uzanma miktarını ölçmek için uygulanmıştır. Testin geçerlilik ve güvenilirliği ICC, oranı 0,87 olarak belirlenmiştir. ${ }^{19}$ MIZY marka duvara sabitlenmiş mezura ile bireyden ilk olarak kolunu düz olarak öne doğru uzatması istenmiş ve uzandığı mesafe kaydedilmiştir. Daha sonra topukları yerden kalkmadan öne uzanabildiği kadar uzanması istenmiş, dengesini kaybetmeden uzanabildiği ve eski pozisyonuna dönebildiği maksimum değer ölçülmüştür. $\mathrm{Bu}$ uygulama $3 \mathrm{kez}$ tekrarlanmış ve bu üç değerin ortalaması alınmıştır.

\section{Araştırmada Uygulanan Çalışmalar}

12 hafta süren araştırmada sırasıyla aşağıda yer alan birim antrenman uygulanmıştır. Power Plate egzersiz grubu hız 25, şiddet low (düşük), süre 30 dakika olacak şekilde antrenmanlarını tamamlamışlardır. Her iki grubun set arası dinlenme süresi 30-45 saniye, hareketler arası dinlenme süresi 1 dakikadır (Çizelge 1, Çizelge 2).

Çizelge 1. Bosu Ball Egzersiz Grubu Programı

\begin{tabular}{|l|l|l|}
\hline Isınma & Ana Evre & Soğuma \\
\hline 10 dakika 7 km hızda koşu & Bosu Ball Squat 3 set 12 tekrar & 10 dk 5 km hizda yürüyüş \\
Jumping jack 2 set 20 tekrar & Bosu Ball Lunge 3 set 12 tekrar & Statik Streching \\
Seel jack 2 set 20 tekrar & Bosu Ball Push Up 3 set 12 tekrar & \\
High knee ups 2 set 20 tekrar & Bosu Ball Triceps Dips 3 set 12 tekrar & \\
& Bosu Ball Plank 3 set 30 saniye & \\
& Bosu Ball Pelvis Bridge 3 set 12 tekrar \\
& Bosu Ball Mountain Climber 3 set 20 tekrar \\
& Bosu Ball Side Plank 3 set 30 saniye & \\
& & \\
\hline
\end{tabular}

Çizelge 2. Power Plate Egzersiz Grubu Programı

\begin{tabular}{|l|l|l|}
\hline Isınma & Ana Evre & Soğuma \\
\hline 10 dakika 7 km hızda koşu & Power Plate Squat 3 set 12 tekrar & $10 \mathrm{dk} \mathrm{5} \mathrm{km} \mathrm{hızda}$ \\
Jumping jack 2 set 20 tekrar & Power Plate Lunge 3 set 12 tekrä \\
Seel jack 2 set 20 tekrar & Power Plate Push Up 3 set 12 tekrar \\
$\begin{array}{l}\text { High knee ups 2 set 20 } \\
\text { tekrar }\end{array}$ & $\begin{array}{l}\text { Statik Streching } \\
\text { Power Plate Triceps Dips 3 set 12 tekrar } \\
\text { Power Plate Plank 3 set 30 saniye } \\
\text { Power Plate Pelvis Bridge 3 set 12 tekrar } \\
\text { Power Plate Mountain Climber 3 set 20 tekrar } \\
\text { Power Plate Side Plank 3 set 30 saniye }\end{array}$ & \\
& & \\
\hline
\end{tabular}




\section{İstatistiksel Analizi}

Verilerin çözümlemesi SPSS (Statistical Package for the Social Sciences) 21.0 paket programında yapılmıştır. Verilere ait tanımlayıcı istatistikler hesaplanmıştır ve normallik testi uygulanmıştır. Normallik testi sonucunda verilerin normal dağılım koşullarını sağlamadığı belirlenmiş ve parametrik olmayan testler ile analizler yapılmıştır. Ön test-son test değerlendirmesinde grup içi Wilcoxon İşaretli Sıralar Testi, gruplar arası karşılaştırmada ise Mann Whitney U Testi uygulanmıştır. Anlam düzeyi 0,05 olarak alınmıştır.

\section{Bulgular}

Çizelge 3'te görüldüğü üzere bosu denek, bosu kontrol, power plate denek, power plate kontrol gruplarının yaş aralığ 1 $26,6 \pm 6,16$, boy uzunluğu $180,2 \pm 7,30$, alt ekstremite uzunluk $100,7 \pm 5,63$, üst ekstremite uzunluk $78,4 \pm 6,48$ bulunmuştur. Çizelge 4'te görüldüğü üzere deney ve kontrol kümelerinin tanımlayıcı özellikleri (yaş, boy uzunluğu, alt ekstremite uzunluk, üst ekstremite uzunluk) ortalama değerleri birbirine paraleldir.

Çizelge 5 incelendiğinde vücut ağırlığı, vücut yağ oranı, y testi sağ ön, y testi sağ yan, y testi sağ çapraz, y testi sol ön, y testi sol yan, y testi sol çapraz, flamingo düşme sayısı ve fonksiyonel uzanma değerleri açısından deney grubuna ait ön test ve son test değişkenleri arasında anlamlı bir farklılık tespit edilmiştir $(p<0,05)$.

Çizelge 6 incelendiğinde vücut ağırlığı, vücut yağ oran1, y testi sağ ön, y testi sağ yan, y testi sağ çapraz, y testi sol ön, y testi sol yan, y testi sol çapraz, flamingo düşme sayısı ve fonksiyonel uzanma değerleri açısından deney grubuna ait ön test ve son test değişkenleri arasında anlamlı bir farklılık tespit edilmiştir $(p<0,05)$. Ayrıca y testi sağ çapraz değerindeki standart sapma değerinin yüksek olması, bosu ball denek grubunun y testi sağ çapraz yönündeki farkın yüksek olmasıyla ilişkilidir.

Çizelge 7 incelendiğinde y testi sol çapraz değerleri açısından bosu ball ve power plate deney grubu ön test değişkeni arasında anlamlı bir farklılık tespit edilirken $(p<0,05)$. Vücut ağırlığ1, vücut yağ oranı, y testi sağ ön, y testi sağ yan, y testi sağ çapraz, y testi sol ön, y testi sol yan, flamingo düşme sayısı ve fonksiyonel uzanma değerleri açısından gruplar arasında anlamlı farklılık tespit edilememiştir $(p>0,05)$.

Çizelge 8 incelendiğinde vücut yağ oranı değerleri açısından bosu ball ve power plate deney grubu son test değişkeni arasında anlamlı bir farklılık tespit edilirken $(p<0,05)$. Vücut ağırlığ 1 , y testi sağ ön, y testi sağ yan, y testi sağ çapraz, y testi sol ön, y testi sol yan, y testi sol çapraz, flamingo düşme sayısı ve fonksiyonel uzanma değerleri açısından gruplar arasında anlamlı farklılık tespit edilememiştir $(p>0,05)$.

Çizelge 3. Katılımcıların Tanımlayııı Özelliklerine Ait Veriler

\begin{tabular}{|c|c|c|}
\hline GRUPLAR & $\mathrm{N}$ & Ortalama \pm Standart Sapma \\
\hline 18-35 yaş arası erkek bireyler & 40 & $26,6 \pm 6,18$ \\
\hline Boy uzunluğu (cm) & 40 & $180,2 \pm 7,30$ \\
\hline Alt ekstremite uzunluk & 40 & $100,7 \pm 5,63$ \\
\hline Üst ekstremite uzunluk & 40 & $78,4 \pm 6,48$ \\
\hline
\end{tabular}

Çizelge 4. Katılımcıların Tanımlayıcı Özelliklerine Ait Veriler

\begin{tabular}{|c|c|c|c|}
\hline GRUPLAR & Değişkenler & N & Ortalama \pm Standart Sapma \\
\hline \multirow{4}{*}{$\begin{array}{c}\text { Bosu } \\
\text { Denek }\end{array}$} & 18 -35 yaş arası erkek bireyler & 10 & $26,0 \pm 7,77$ \\
\cline { 2 - 4 } & Boy uzunluğu (cm) & 10 & $183,4 \pm 5,71$ \\
\cline { 2 - 4 } & Alt ekstremite uzunluk & 10 & $103,7 \pm 3,56$ \\
\cline { 2 - 4 } & Üst ekstremite uzunluk & 10 & $79 \pm 3,97$ \\
\hline \multirow{4}{*}{$\begin{array}{c}\text { Bosu } \\
\text { Kontrol }\end{array}$} & 18-35 yaş arası erkek bireyler & 10 & $26 \pm 6,02$ \\
\cline { 2 - 4 } & Boy uzunluğu (cm) & 10 & $177,4 \pm 9,60$ \\
\cline { 2 - 4 } & Alt ekstremite uzunluk & 10 & $98,3 \pm 6,70$ \\
\hline \multirow{3}{*}{$\begin{array}{c}\text { Power } \\
\text { Plate } \\
\text { Denek }\end{array}$} & Üst ekstremite uzunluk & 10 & $77,2 \pm 7,92$ \\
\cline { 2 - 4 } & $18-35$ yaş arası erkek bireyler & 10 & $24,1 \pm 4,72$ \\
\cline { 2 - 4 } & Boy uzunluğu (cm) & 10 & $182,6 \pm 6,25$ \\
\cline { 2 - 4 } & Alt ekstremite uzunluk & 10 & $103,6 \pm 5,18$ \\
\hline \multirow{3}{*}{$\begin{array}{c}\text { Power } \\
\text { Plate } \\
\text { Kontrol }\end{array}$} & $18-35$ yaş arası erkek & 10 & $78,8 \pm 7,69$ \\
\cline { 2 - 4 } & bireyler & 10 & $29,9 \pm 5,23$ \\
\cline { 2 - 4 } & Blt ekstremite uzunluk & 10 & $177,4 \pm 5,64$ \\
\cline { 2 - 4 } & Üst ekstremite uzunluk & 10 & $97,3 \pm 3,83$ \\
\hline
\end{tabular}


Çizelge 5. Power Plate Deney Grubu ön test ve son test değişkenlerinin Wilcoxon İşaretli Sıralar Testi analiz sonuçları

\begin{tabular}{|c|c|c|c|c|}
\hline \multirow{2}{*}{ Değişkenler } & Ön test & Son test & \multirow{2}{*}{$\mathbf{Z}$} & \multirow{2}{*}{$p$} \\
\hline & $\bar{x} \pm \mathbf{S d}$ & $\bar{x} \pm$ Sd & & \\
\hline Vücut ă̆ırlığı & $81,9 \pm 8,12$ & $79,9 \pm 7,94$ & $-2,295$ & $0,022 *$ \\
\hline Vücut yağ oranı & $12,4 \pm 4,17$ & $10,7 \pm 4,12$ & $-2,805$ & $0,005 *$ \\
\hline Y testi sağ ön (cm) & $59,5 \pm 9,64$ & $68,4 \pm 9,24$ & $-2,807$ & $0,005 *$ \\
\hline Y testi sağ yan & $86,2 \pm 9,18$ & $94,4 \pm 8,99$ & $-2,809$ & $0,005 *$ \\
\hline Y testi sağ çapraz & $86,5 \pm 10,6$ & $92,9 \pm 10,8$ & $-2,807$ & $0,005 *$ \\
\hline Y testi sol ön & $60,0 \pm 7,27$ & $67,3 \pm 7,66$ & $-2,812$ & $0,005 *$ \\
\hline Y testi sol yan & $90,9 \pm 10,4$ & $98,4 \pm 10,6$ & $-2,810$ & $0,005 *$ \\
\hline Y testi sol çapraz & $81,8 \pm 8,76$ & $92,2 \pm 9,68$ & $-2,807$ & $0,005 *$ \\
\hline Flamingo (düşme sayısı) & $11,0 \pm 5,98$ & $5,60 \pm 3,02$ & $-2,821$ & $\mathbf{0 , 0 0 5 *}$ \\
\hline Fonksiyonel uzanma (cm) & $44,2 \pm 4,77$ & $56,4 \pm 3,02$ & $-2,812$ & $0,005 *$ \\
\hline
\end{tabular}

Çizelge 6. Bosu Ball Deney Grubu ön test ve son test değişkenlerinin Wilcoxon İşaretli Sıralar Testi analiz sonuçları

\begin{tabular}{|c|c|c|c|c|}
\hline \multirow{2}{*}{ Değişkenler } & Ön test & Son test & \multirow{2}{*}{$\mathbf{Z}$} & \multirow{2}{*}{$p$} \\
\hline & $\bar{x} \pm \mathbf{S d}$ & $\bar{x} \pm \mathbf{S d}$ & & \\
\hline Vücut ă̆ırlığı & $81,5 \pm 8,16$ & $80,5 \pm 8,27$ & $-2,244$ & $0,025 *$ \\
\hline Vücut yağ oranı & $15,6 \pm 3,44$ & $13,9 \pm 3,00$ & $-2,497$ & $\mathbf{0 , 0 1 3} *$ \\
\hline Y testi sağ ön (cm) & $59,5 \pm 9,80$ & $67,0 \pm 9,42$ & $-2,810$ & $0,005 *$ \\
\hline Y testi sağ yan & $94,9 \pm 13,6$ & $104,4 \pm 15,7$ & $-2,809$ & $0,005 *$ \\
\hline Y testi sağ çapraz & $92,7 \pm 17,3$ & $99,4 \pm 17,6$ & $-2,807$ & $0,005 *$ \\
\hline Y testi sol ön & $59,1 \pm 6,85$ & $64,6 \pm 7,93$ & $-2,814$ & $0,005 *$ \\
\hline Y testi sol yan & $91,1 \pm 11,3$ & $99,7 \pm 15,3$ & $-2,807$ & $0,005 *$ \\
\hline Y testi sol çapraz & $93,4 \pm 12,2$ & $100,6 \pm 15,3$ & $-2,719$ & $0,007 *$ \\
\hline Flamingo (düşme sayısı) & $11,2 \pm 5,67$ & $5,70 \pm 3,02$ & $-2,805$ & $0,005 *$ \\
\hline Fonksiyonel uzanma (cm) & $49,4 \pm 8,72$ & $59,6 \pm 9,67$ & $-2,805$ & $0,005 *$ \\
\hline
\end{tabular}
$* p<0,05$

Çizelge 7. Bosu Ball ve Power Plate deney grubu ön test değişkenlerinin Mann Whitney U Testi analiz sonuçları

\begin{tabular}{|c|c|c|c|c|}
\hline \multirow{2}{*}{ Değişkenler } & Ön test & Ön test & \multirow{2}{*}{$\mathbf{Z}$} & \multirow{2}{*}{$p$} \\
\hline & $\bar{x} \pm \mathbf{S d}$ & $\bar{x} \pm \mathbf{S d}$ & & \\
\hline Vücut ağırlığı & $81,5 \pm 8,16$ & $81,9 \pm 8,12$ & $-0,000$ & 1,000 \\
\hline Vücut yağ oranı & $15,6 \pm 3,44$ & $12,4 \pm 4,17$ & $-1,816$ & 0,069 \\
\hline Y testi sağ ön (cm) & $59,5 \pm 9,80$ & $59,5 \pm 9,64$ &,- 303 & 0,762 \\
\hline Y testi sağ yan & $94,9 \pm 13,6$ & $86,2 \pm 9,18$ & $-1,476$ & 0,140 \\
\hline Y testi sağ çapraz & $92,7 \pm 17,3$ & $86,5 \pm 10,6$ &,- 492 & 0,623 \\
\hline Y testi sol ön & $59,1 \pm 6,85$ & $60,0 \pm 7,27$ &,- 304 & 0,761 \\
\hline Y testi sol yan & $91,1 \pm 11,3$ & $90,9 \pm 10,4$ &,- 076 & 0,940 \\
\hline Y testi sol çapraz & $93,4 \pm 12,2$ & $81,8 \pm 8,76$ & $-1,970$ & $0,049 *$ \\
\hline Flamingo (düşme sayısı) & $11,2 \pm 5,67$ & $11,0 \pm 5,98$ &,- 114 & 0,909 \\
\hline Fonksiyonel uzanma $(\mathrm{cm})$ & $49,4 \pm 8,72$ & $44,2 \pm 4,77$ & $-1,327$ & 0,185 \\
\hline
\end{tabular}


Çizelge 8. Bosu Ball ve Power Plate deney grubu son test değişkenlerinin Mann Whitney U Testi analiz sonuçları

\begin{tabular}{|c|c|c|c|c|}
\hline \multirow{2}{*}{ Değişkenler } & Son test & Son test & \multirow{2}{*}{$\mathbf{Z}$} & \multirow{2}{*}{$p$} \\
\hline & $\bar{x} \pm$ Sd & $\bar{x} \pm \mathbf{S d}$ & & \\
\hline Vücut ağırlığı & $80,5 \pm 8,27$ & $79,9 \pm 7,94$ &,- 340 & 0,734 \\
\hline Vücut yağ oranı & $13,9 \pm 3,00$ & $10,7 \pm 4,12$ & $-1,967$ & $0,049 *$ \\
\hline Y testi sağ ön (cm) & $67,0 \pm 9,42$ & $68,4 \pm 9,24$ &,- 152 & 0,880 \\
\hline Y testi sağ yan & $104,4 \pm 15,7$ & $94,4 \pm 8,99$ & $-1,401$ & 0,161 \\
\hline Y testi sağ çapraz & $99,4 \pm 17,6$ & $92,9 \pm 10,8$ &,- 757 & 0,449 \\
\hline Y testi sol ön & $64,6 \pm 7,93$ & $67,3 \pm 7,66$ &,- 607 & 0,544 \\
\hline Y testi sol yan & $99,7 \pm 15,3$ & $98,4 \pm 10,6$ &,- 379 & 0,705 \\
\hline Y testi sol çapraz & $100,6 \pm 15,3$ & $92,2 \pm 9,68$ & $-1,401$ & 0,161 \\
\hline Flamingo (düşme sayısı) & $5,70 \pm 3,02$ & $5,60 \pm 3,02$ &,- 114 & 0,909 \\
\hline Fonksiyonel uzanma (cm) & $59,6 \pm 9,67$ & $56,4 \pm 3,02$ &,- 871 & 0,384 \\
\hline
\end{tabular}

\section{Tartışma}

Araştırmaya düzenli gelen ve gönüllü olarak katılan 20 deney ve 20 kontrol grubu olmak üzere 40 kişi haftanın 3 günü günde bir saat olarak çalışmalara 10 power plate 10 bosu olmak üzere 20 kişilik deney grubu, 10 power plate 10 bosu olmak üzere 20 kişilik kontrol grubu belirlenmiştir. Power plate deney grubunun yaş ortalamaları $24,1 \pm 4,72$ yıl, boy ortalamaları $182,6 \pm 6,25 \mathrm{~cm}$, alt ekstremite uzunluk $103,6 \pm 5,18 \mathrm{~cm}$, üst ekstremite uzunluk $78.8 \pm 7,69 \mathrm{~cm}$ 'dir. Power plate kontrol grubunun yaş ortalamaları 29,9 $\pm 5,23$ yıl, boy ortalamaları $177,4 \pm 5,64 \mathrm{~cm}$, alt ekstremite uzunluk $97,3 \pm 3,83 \mathrm{~cm}$, üst ekstremite uzunluk $78.5 \pm 6,45 \mathrm{~cm}$ 'dir. Bosu deney grubunun yaş ortalamaları $26.0 \pm 7,77$ yıl, boy ortalamaları $183,4 \pm 5,71 \mathrm{~cm}$, alt ekstremite uzunluk $103,7 \pm 3,56 \mathrm{~cm}$, üst ekstremite uzunluk 79,0 $3,97 \mathrm{~cm}$ 'dir. Bosu kontrol grubunun yaş ortalamaları $26,0 \pm 6,02$ yıl, boy ortalamaları $177,4 \pm 9,60 \mathrm{~cm}$, alt ekstremite uzunluk $98,3 \pm 6,70 \mathrm{~cm}$, üst ekstremite uzunluk 77,2 $\pm 3,92 \mathrm{~cm}$ 'dir. Power plate kontrol grubuna ait ön test-son test değişkenleri arasında anlamlı bir farkl1lık bulunmazken $(p>0,05)$, deney grubunda ön test-son test verilerinde vücut ağırlığı, vücut yağ oranı, y testi sağ ön, y testi sağ yan, y testi sağ çapraz, y testi sol ön, y testi sol yan, y testi sol çapraz, flamingo düşme sayısı ve fonksiyonel uzanma değerleri açısından deney grubuna ait ön test-son test değişkenleri arasında anlamlı bir farklılık bulunmuştur $(p<0,05)$. Power plate ile yapılan egzersiz programının denge gelişiminin etkisinin yanında vücut ağırlığı ve vücut yağ oranında da azalmalar görülmüştür. Araştırmamızı destekler nitelikteki çalışmalar; Power plate ile uygulanan egzersizlerde denge ve yürüyüşü geliştirdiğine yönelik sonuçlar bulunmuştur. ${ }^{20}$

On iki hafta boyunca 48 sağlıklı erkek birey üzerinde yapılan tüm beden vibrasyon antrenmanında kullanılan power plate cihazının deney grubunun statik ve dinamik denge değerlerinde anlamlı bir şekilde geliştiği gözlemlenmiştir. 21 Yaş aralığı 25-45 olan 20 kişiden oluşan denek grubu, haftada $3 \mathrm{kez}$, günde 45 dakika olarak toplamda 24 hafta boyunca power plate ile uygulanan egzersiz sonrası vücut ağırlığı ve vücut yağ oranında oldukça anlamlı azalma meydana gelmiştir.22
Bosu ball kontrol grubuna ait ön test-son test değişkenleri arasında anlamlı bir farklılık tespit edilmezken $(p>0,05)$, deney grubu incelendiğinde ön test-son test verilerinde vücut ağırlığı, vücut yağ oranı, y testi sağ ön, y testi sağ yan, y testi sağ çapraz, y testi sol ön, y testi sol yan, y testi sol çapraz, flamingo düşme sayısı ve fonksiyonel uzanma değerleri açısından deney grubuna ait ön test-son test değişkenleri arasında anlamlı bir farklılık tespit edilmiştir $(p<0,05)$. Bosu ball ile yapılan egzersiz programının denge gelişiminin etkisinin yanında vücut ağırlığı ve vücut yağ oranında da azalmalar görülmüştür. Araştırmamızı destekler nitelikteki çalışmalar;

Farklı gruplar üzerinde, farklı egzersiz programları ile farklı test protokolleri kullanılarak yürütülmesine rağmen literatürde bosu veya denge tahtası ile denge egzersizlerinin etkilerini değerlendiren çalışmalar olumlu sonuçlar göstermiştir. ${ }^{23,24,25}$

52 aktif sağlıklı üniversite öğrencisi ile yapılandırılmış denge egzersizlerini içeren, sekiz hafta boyunca haftada 3 gün, denge tahtası veya bosu üzerinde yapılan denge egzersizlerinin statik ve dinamik dengeyi olumlu yönde geliştirdiğini saptamışlardır. ${ }^{26}$

19-28 yaşları arasında sağlıklı erkek öğrencilerin bosu ile yapılan kuvvet çalışmalarının denge gelişimini olumlu yönde etkilediğini, ayrıca bosu gibi stabil olmayan yüzeylerdeki egzersizin stabil olana göre kas aktivitesinde artış sağladığ gözlemlenmekte olup yüzeyin hareketlilik seviyesi ile kas aktivitesi arasında bir ilişki olduğunu bildirmişlerdir. ${ }^{27}$ Sağlıklı bireylerde standart denge eğitimi olarak tanımlanan bosu ve denge tahtaları ile 18 bireye 8 hafta boyunca haftada 3 gün uygulanan denge eğitimi çalışmalarının dinamik-statik dengede ve fonksiyonel parametrelerde uygulama sonrasında artış ve fark bulunmuştur. ${ }^{28}$

Denge gelişimi için yapılan egzersizlerde bosu, şişme disk ve şişme minderler ile yapılan çalışma sonrasında deney grubunun denge ölçümlerinde anlamlı derecede gelişme ve alt ekstremite asimetrisinde azalma elde elde ettiklerini bildirmişlerdir. ${ }^{29}$

Voleybolcularda denge antrenmanlarının yorgunluk ortamında propriosepsiyon duyusuna etkisi başlıklı çalışmasında farklı ekipmanlarla denge egzersizlerinin 
uygulandığı çalışma sonunda çift ayak statik ve dinamik denge ön test-son test ölçüm değerleri arasında istatistiksel olarak anlamlı bir farklılık bulunmuş $(p<0,05)$ olup özellikle dinamik dengenin geliştirilmesinde farklı ekipmanlar kullanımının önemi vurgulanmıştır. ${ }^{30}$

Futbolcularda 8 hafta uygulanan core egzersizlerinin statik dengeyi geliştirmediğini, daha sonra yapılacak çalışmalar için bosu topu ve denge tahtası gibi hareketli nesneler üzerinde bu egzersizlerin yapılmasının önemli sonuçlar ortaya koyabileceği önerisinde bulunmuştur. ${ }^{31}$

\section{Sonuç}

On iki hafta süresince deney gruplarına vücut ağırlığı ile uygulanan bosu ve power plate üzerinde yapılan düzenli ve sistemli egzersizlerin bireylerin denge değerlerinde anlaml yönde farklılık bulunmuştur ( $p<0,05)$. Ayrıca vücut ağırlığı ve vücut yağ oranında anlamlı oranda azalma olduğu gözlemlenmiştir. Özellikle performans sporlarında denge gelişiminde hızlı aşama gösterilmesine büyük fark yaratacağı düşünülmektedir.

\section{Teşekkür}

Yazarlar olarak, çalışmamıza istatistiksel analizlerde destek sağlayan Arş. Gör. Muhammet Eyüp UZUNER'e teşekkür ederiz. Bu makale, ilk yazar tarafından yazılan ve ikinci yazar tarafından yönetilen yüksek lisans tezinden üretilmiştir.

\section{Çıkar Çatışması Beyanı}

Yazarların herhangi bir çıkara dayalı ilişkisi yoktur.

\section{Araştırmanın Etik Yönü}

Çalışma boyunca Helsinki Deklarasyonu kurallarına riayet edilmiştir.

\section{Etik Onay/Hasta Onamı}

Araştırmanın etik onayı, Kocaeli Üniversitesi Girişimsel Olmayan Klinik Araştırmalar Etik Kurulu'ndan 2019/61 sayılı proje numarası ve 2019/04.14 karar numarası ile 20.02.2019 tarihinde alınmıştır.

\section{Maddi Destek}

Çalışmayı maddi olarak destekleyen kişi/kuruluş yoktur.

\section{Kaynaklar}

1. Muratlı S. Çocuk ve spor antrenman bilimi yaklaşımıyla. 1. Bask1. Ankara: Nobel Basımevi; 2003:201-219.

2. Kirichner G. Physical education for elementary school children. USA: Brown Publishers Iowa; 2001:30-31.

3. Liman N, Güzel NA. Aerobik-Step ve pilates egzersizlerinin kuvvet, esneklik, anaerobik güç, denge ve vücut kompozisyonuna etkisi. Gazi Beden Eğitimi ve Spor Bilimleri Dergisi. 2008;13(4), 3-12.

4. Coşkun S. Denge Antrenmanlarının Kara Pentatloncularda Firlatmada İsabetlilik Oranına Denge ve Koordinasyona Üzerine Etkisi [Doktora Tezi]. Ankara, Türkiye: Gazi Üniversitesi; 2012.

5. Şahin $G$, Şeker H, Yeşilırmak M, Çadır A. Denge diski egzersizlerinin dinamik denge ve duruş kontrolü üzerindeki etkisinin incelenmesi. Spor ve Performans Araştırmaları Dergisi. 2015;6(1), 50-57. doi:10.17155/spd.20761

6. Son SM, Park MK, Lee NK. Influence of resistance exercise training to strengthen muscles across multiple joints of the lower limbs on dynamic balance functions of stroke patients. $J$ Phys Ther Sci. 2014;26(8), 1267-1269. doi:10.1589/jpts.26.1267

7. LephartS M, Princivero DM, Giraldo JL, Fu FH. The role of proprioception in the management and rehabilitation of athletic injuries. Am $J$ Sports Med.. 2007;25,130-137. doi:10.1177/036354659702500126

8. Cug M. Effects of swiss ball training on knee joint reposition sense, core strength and dynamic balance in sedentary collegiate students. Ankara: Sciences Of Middlee East technical University; 2012.

9. Erkmen N. Futbolcularda Yorğunluğun Denge Performansına Etkisi. Sport Sciences. 2009;4(4), 289-299.

10. Cardinale M, Bosco C. The use of vibration as an exercise intervention. Exerc Sport Sci Rev. 2003;31(1), 3-7. doi:10.1097/00003677-200301000-00002

11. Hoyo Lora MD, Romero Granados S, Sañudo Corrales FDB, Carrasco Páez L. Whole body vibration: Acute and residual effect on the explosive strengh. J. Hum. Sport Exerc. 2010;5(2), 188-195. doi:10.4100/jhse.2010.52.08

12. Verschueren SM, Roelants M, Delecluse C, Swinnen S, Vanderschueren D, Boonen S. Effect of 6-month whole body vibration training on hip density, muscle strength, and postural control in postmenopausal women: a randomized controlled pilot study. J Bone Miner Res. 2004;19(3), 352-359. doi:10.1359/jbmr.0301245

13. Uğur E, Baysaling Ö. Herkes İçin Spor, Vücut Geliştirme, Fitness ve Formda Kalma. İstanbul: İlpress Basım ve Yayın; 2005.

14. Yaggie JA, Campbell BM. Effects of balance training on selected skills. J Strength Cond Res. 2006;20(2), 422-428. doi:10.1519/00124278-200605000-00031

15. Ruiz R, Richardson MT. Functional balance training using a domed device. Army War Collage Carlisle Barracks Pa Physical Fitness Rerearch Institute; 2005. doi:10.1519/00126548-200502000-00010

16. Türk N. Sedanter bayanlarda bosu egzersizin fiziksel uygunluk ve psikososyal değişimlerine etkisi. [Yüksek Lisans Tezi]. Çorum, Türkiye: Hitit Üniversitesi; 2016.

17. Tsigilis N, Douda H, Tokmakidis SP. Test-retest reliability of the Eurofit test battery administered to university students. Perceptual and motor skills, 2002;95(3_suppl), 1295-1300. doi:10.2466/pms.2002.95.3f.1295

18. Plisky PJ, Gorman PP, Butler RJ, Kiesel KB, Underwood FB, Elkins B. The reliability of an instrumented device for measuring components of the star excursion balance test. $N \mathrm{Am}$ J Sports Phys Ther. 2009; NAJSPT, 4(2), 92.

19. Lin YH, Tang YW, Chen TR, Wang CY. A reliability study for standing functional reach test using modified and traditional rulers. Percept Mot Skills. 2012;115(2), 512-520. doi:10.2466/15.03.10.pms.115.5.512-520

20. Ebersbach G, Edler D, Kaufhold O, Wissel J. Whole body vibration versus conventional physiotherapy to improve balance and gait in Parkinson's disease. Arch Phys Med Rehabil. 2008;89(3), 399-403. doi:10.1016/j.apmr.2007.09.031

21. Koç G. Tüm Beden Vibrasyon Antrenmanının Nöromuskuler Performans Üzerine Etkisi. [Yüksek Lisans Tezi]. Antalya, Türkiye: Akdeniz Üniversitesi; 2013.

22. Aktaş B, Kolukısa, A. Power Plate Çalışmalarına Katılan Bireylerin Anatomik ve Fizyolojik Yapılarındaki Gelişmelerinin Araştırılması. [Yüksek Lisans Tezi]. Sakarya, Türkiye: Sakarya Üniversitesi; 2010.

23. Silva PB, Mrachacz-Kersting N, Oliveira AS, Kersting UG. Effect of wobble board training on movement strategies to maintain equilibrium on unstable surfaces. Hum Mov Sci. 2018;58(1), 231-238. doi:10.1016/j.humov.2018.02.006

24. Cuğ M, Duncan A, Wikstrom E. Comparative effects of different balance-training-progression styles on postural control and ankle force production: a randomized controlled trial. J Athl Train. 2016;51(2), 101-110. doi:10.4085/10626050-51.2.08

25. Lubetzky-Vilnai A, McCoy SW, Price R, Ciol MA. Young adults largely depend on vision for postural control when standing on a BOSU ball but not on foam. J Strength Cond Res. 2015;29(10), 2907-2918. doi:10.1519/jsc.0000000000000935

26. Nalçakan GR, Yol Y. Balance board vs balance ball: which one is superior in enhancing static and dynamic balance abilities on 
healthy university students. Int J Sport, Exer \& Train Sci, 2020;6 (2), 57-64. doi:10.18826/useeabd.715111

27. Şan G, Biçer M, Pancar Z. Ozdal M. The effects of strength exercises done with Bosu for 8 weeks on balance and anaerobic performance. Journal of Social and Humanities Sciences Research. 2019;6(47), 4327-4334. doi: http://dx.doi.org/10.26450/jshsr.1629

28. Haksever B, Düzgün İ, Deniz Y, Baltacı G. Sağlıklı Bireylere Standart Eğitiminin Dinamik, Statik Denge ve Fonksiyonellik Üzerine Etkileri Gazi Üniversitesi Sağlık Bilimleri Dergisi. 2017;2(3), 40-49.

29. Sannicandro I, Cofano G, Rosa RA, Piccinno A. Balance training exercises decrease lower-limb strength asymmetry in young tennis players. J Sports Sci Med. 2014;13(2), 397. doi:10.1136/bjsports-2016-097372.248

30. Can B. Bayan Voleybolcularda Denge Antrenmanlarının Yorgunluk Ortamında Propriosepsiyon Duyusuna Etkisi. Etkisi [Doktora Tezi]. Ankara, Türkiye: Gazi Üniversitesi; 2008.

31. Yıldızer G. 8 Haftalık Merkez Sabitleme Antrenmanlarının Çocuk Futbolcularda Statik Denge Performansına Etkisi. [Yüksek Lisans Tezi].Ankara, Türkiye: Orta Doğu Teknik Üniversitesi; 2014. 